\title{
Clinicopathological Study of Sinonasal Masses
}

\author{
Prashant Shivaji Mane* and Shubhangi Vinayak Agale
}

Department of Pathology, Grant Government Medical College, Mumbai Maharashtra India.

\begin{abstract}
Background: Sinonasal mass is a common finding in the Otorhinolaryngology Department. These can be non-neoplastic or neoplastic. Nasal obstruction is the most common clinical presentation. Imaging studies are not always conclusive in these cases. So, the present study aimed at clinical presentation and histopathological classification of sinonasal masses.

Methods: All the specimens received as sinonasal masses were included in the present study. The tissues were routinely processed for histopathological examination and were stained by Hematoxylin and Eosin stain. Special stains were used wherever required. Immunohistochemistry was carried on cases with diagnostic difficulties.

Results: Non-neoplastic lesions outnumbered the neoplastic lesions. Among the neoplastic lesions, benign tumours were more common than malignant tumours. Non-neoplastic lesions and benign tumours were commonly seen in middle age group while malignant tumours were seen in adult patients. Males were predominantly affected in non-neoplastic lesions and benign tumours. Malignant tumours showed female dominance. Nasal obstruction was the most common complaint. Overall, inflammatory nasal polyps were most common lesions. Inverted papillomas were most common benign tumours. Sinonasal undifferentiated carcinomas accounted for majority of malignant tumours.
\end{abstract}

Conclusion: Sino-nasal masses or polyps can be non-neoplastic or neoplastic lesions and histopathological examination remains the mainstay in differentiating these lesions.

Keywords: Nasal Cavity, Paranasal Sinus, Polyp, Nasal Obstruction.

\section{Introduction}

The nasal cavity and paranasal sinuses are collectively referred as sinonasal tract. Sinonasal area is exposed to various infective agents, chemicals, antigens, mechanical and many other influences. These deleterious exposures lead to formation of tumour like and neoplastic conditions. ${ }^{[1]}$ Most of these lesions in Otorhinolaryngology Department present as polypoid masses, making it difficult to distinguish non-neoplastic polyps from polypoid neoplasms clinically. ${ }^{[2]}$ Inflammatory polyps are a common cause of nasal obstruction, with a prevalence of $4 \%$ in the general population. ${ }^{[3]}$ Benign tumours are relatively common, but malignant neoplasms are rare. Malignant tumours account for $0.2 \%$ to $0.8 \%$ of total malignancies and only $3 \%$ of all malignant tumours of upper aerodigestive tract. ${ }^{[4]}$ Nasal obstruction is the most common symptom. Other symptoms include nasal discharge, epistaxis and disturbances of smell. ${ }^{[5]}$ Fine needle aspiration of paranasal sinus lesions is difficult due to closed architecture, and only one study has been documented in the literature. ${ }^{[6]}$ Intraoperative cytology and frozen section examinations of lesions of nose and paranasal sinuses are useful, quick, and reliable diagnostic technique for rapid and early diagnosis in the operation theatre and can be used as an adjunct to histopathology for better management of patients. ${ }^{[7]}$
The presenting features, symptomatology and advanced imaging technique help to reach a presumptive diagnosis but histopathological examination remains the mainstay of final definitive diagnosis. ${ }^{[8,9]}$

The present study was carried to study the age and sex distribution of sinonasal masses, their clinical presentation and to categorize them histopathologically.

\section{Materials and Methods}

The present study was three year retrospective and two year prospective, carried out in the Department of Pathology, Grant Govt. Medical College \& Sir J. J. Group of Hospital, Mumbai.

All the specimens received as sinonasal mass were included in the present study. Lesions of the nasopharyngeal region and lesions arising from the external nose were not included in the study. The tissues were routinely processed for histopathological examination and were stained by Hematoxylin and Eosin stain. Special stains were used wherever required. The clinical details and imaging studies were obtained from medical record section. Detailed microscopic study was done and then the final diagnosis was given. Typing of the neoplastic lesions was carried out following WHO classification. Immunohistochemistry was carried on cases with diagnostic difficulties. 
Approval for the study was given by the Institutional Ethical Committee.

\section{Result}

Out of 36,829 specimens received during 5 year study period, 135 specimens $(0.36 \%)$ involved lesions of nose and paranasal sinuses. Repeat biopsies were received in 4 cases. In 5 cases opinion was not possible due to inadequate biopsy or necrotic tissue, so these cases were excluded from the study. Thus, final study included total 126 cases.

Non-neoplastic lesions $(83.33 \%)$ outnumbered the neoplastic lesions (16.67\%). Among the neoplastic lesions, benign tumours $(11.9 \%)$ were more common than malignant tumours $(4.76 \%)$ (Table1). Youngest patient affected was 19 years and oldest was 77 years. Non-neoplastic lesions and benign tumours were commonly seen in $3^{\text {rd }}-5^{\text {th }}$ decade while malignant tumours were seen in adult patient in $6^{\text {th }}$ and $7^{\text {th }}$ decade (Table 2). Males were predominantly affected in non-neoplastic lesions and benign tumours. Malignant tumours showed female dominance (Table 3). Nasal obstruction was the most common complaint in all non-neoplastic and neoplastic lesions. Epistaxis was also common presentation in neoplastic lesions (Table 4).

Overall, inflammatory nasal polyps were most common lesions (69.04\%). These were further sub-classified as edematous or eosinophilic polyp (68.96\%), fibroinflammatory polyp (21.83\%) and polyp with seromucinous gland hyperplasia (9.19\%). Fungal rhinosinusitis and rhinosporidiosis were other non-neoplastic lesions. Noninvasive fungal rhinosinusitis was seen in $60 \%$ cases and invasive fungal rhinosinusitis in $40 \%$ cases. Fungal ball was most common presentation (40\%). Inverted papillomas were most common benign tumours followed by angiofibroma. Sinonasal undifferentiated carcinomas constituted $66.66 \%$ of malignant tumours.

Table 1: Distribution of lesions.

\begin{tabular}{|l|c|c|}
\hline Histopathological diagnosis & No. of cases & Percentage (\%) \\
\hline I. Non-neoplastic lesions & 105 & 83.33 \\
\hline Inflammatory nasal polyp & 87 & 69.04 \\
\hline Fungal rhinosinusitis & 15 & 11.90 \\
\hline Rhinosporidiosis & 3 & 2.38 \\
\hline II. Benign tumours & 15 & 11.90 \\
\hline Inverted papilloma & 6 & 4.76 \\
\hline Angiofibroma & 4 & 3.17 \\
\hline Solitary fibrous tumour & 1 & 0.79 \\
\hline Lobular capillary hemangioma & 1 & 0.79 \\
\hline Osteoid osteoma & 1 & 0.79 \\
\hline Ossifying fibroma & 1 & 0.79 \\
\hline Giant cell reparative granuloma & 1 & 0.79 \\
\hline III) Malignant tumours & 6 & 4.76 \\
\hline Squamous cell carcinoma & 1 & 0.79 \\
\hline Sino-nasal undifferentiated carcinoma & 4 & 3.17 \\
\hline Neuroendorinetumour & 1 & 0.79 \\
\hline Total & 126 & 100 \\
\hline
\end{tabular}

Table 2: Age wise distribution of lesions.

\begin{tabular}{|l|c|c|c|}
\hline Age in years & Non-neoplastic lesions (\%) & Benign tumours(\%) & Malignant tumours(\%) \\
\hline $1-10$ & 0 & 0 & 0 \\
\hline $11-20$ & 7.6 & 20 & 0 \\
\hline $21-30$ & 30.5 & 13.3 & 16.67 \\
\hline $31-40$ & 25.7 & 26.7 & 0 \\
\hline $41-50$ & 22.9 & 20 & 0 \\
\hline $51-60$ & 7.6 & 6.7 & 50.0 \\
\hline $61-70$ & 3.8 & 13.3 & 0 \\
\hline $71-80$ & 1.9 & 00 & $\mathbf{1 0 0}$ \\
\hline Total & $\mathbf{1 0 0}$ & $\mathbf{1 0 0}$ & \\
\hline
\end{tabular}


Table 3: Gender wise distribution of lesions

\begin{tabular}{|c|c|c|c|}
\hline Sex & Non-neoplastic lesions (\%) & Benign tumours(\%) & Malignant tumours(\%) \\
\hline Male & 57.1 & 80 & 33.33 \\
\hline Female & 42.9 & 20 & 66.67 \\
\hline
\end{tabular}

Table 4: Clinical features

\begin{tabular}{|l|c|c|c|}
\hline Clinical features & Non-neoplastic lesions (\%) & Benign tumours(\%) & Malignant tumours(\%) \\
\hline Nasal obstruction & 84.76 & 80 & 71.4 \\
\hline Nasal discharge & 55.23 & 53.3 & 42.8 \\
\hline Headache & 18.09 & 6.7 & 28.6 \\
\hline Epistaxis & 22.85 & 53.3 & 71.4 \\
\hline Anosmia/ Hyposmia & 37.14 & 13.3 & 28.6 \\
\hline Breathlessness & 11.42 & 0 & 0 \\
\hline Facial swelling & 0.95 & 6.7 & 42.8 \\
\hline Eye related symptoms & 4.76 & 0 & 28.6 \\
\hline
\end{tabular}

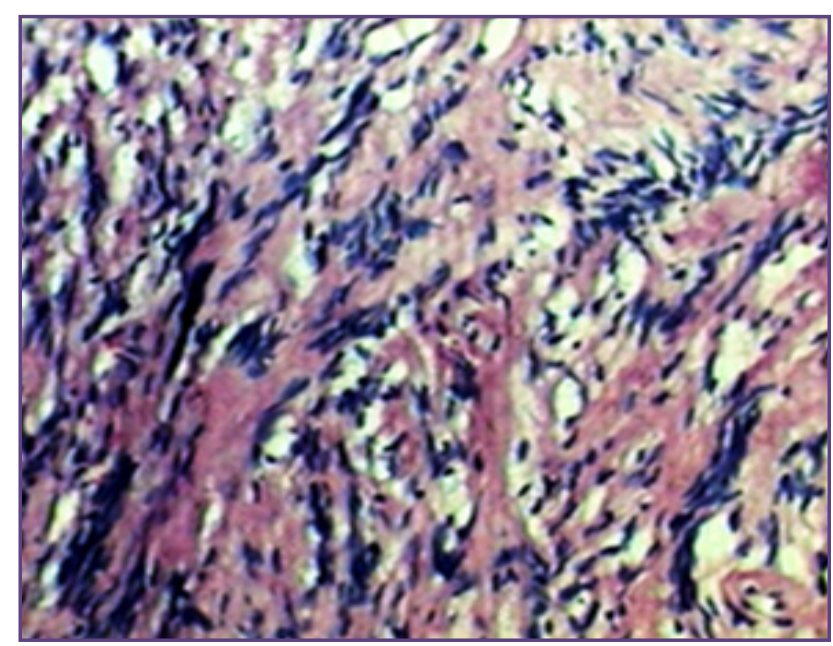

Fig. 1a: Solitary fibrous tumor showing spindle cells arranged in fascicles with indistinct cytoplasmic margins and plump to spindle nuclei (H\&E, X400).

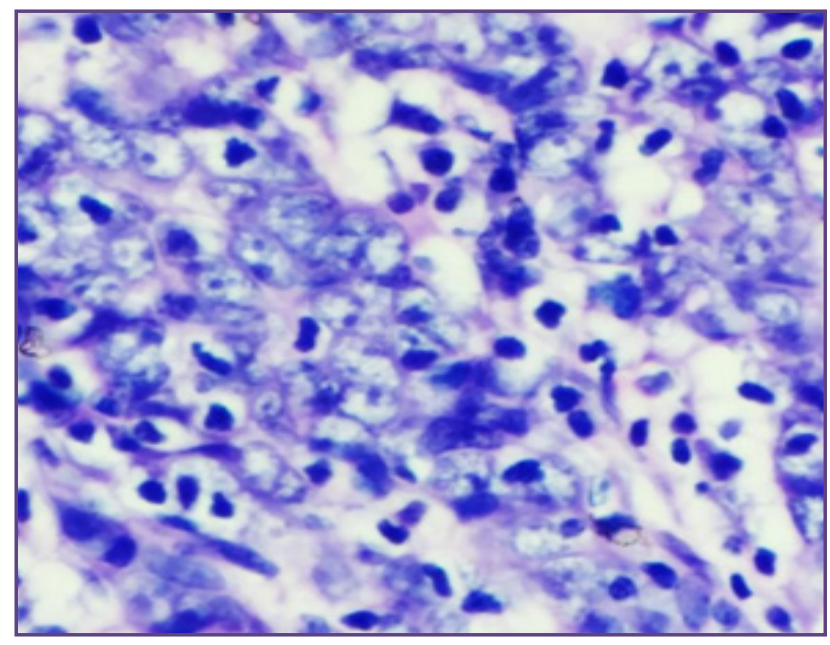

Fig 2a: Sinonasal undifferentiated carcinoma showing large tumor cells with scant cytoplasm, vesicular nuclei and prominent nucleoli (H\&E, X400).

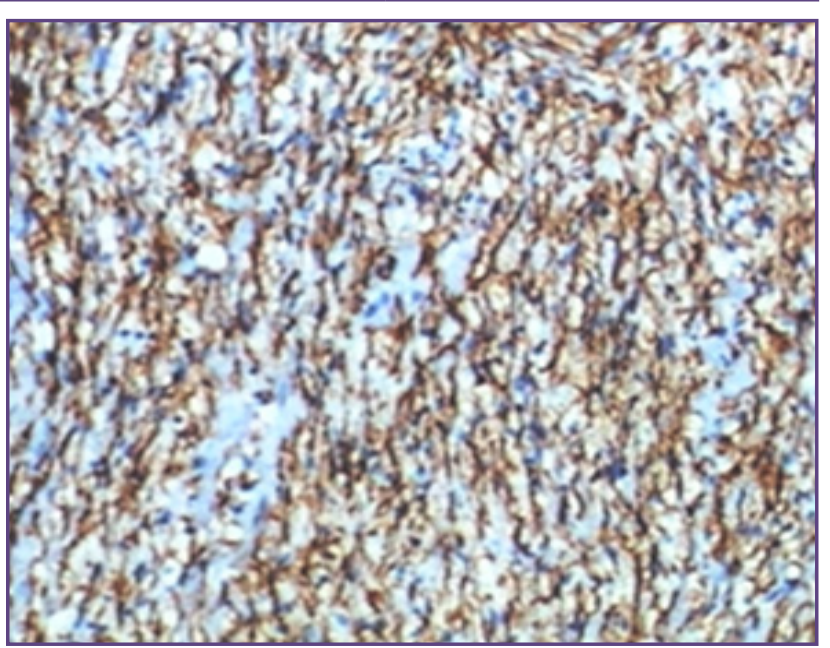

Fig. 1b: Solitary fibrous tumor showing diffuse cytoplasmic positivity for CD34.

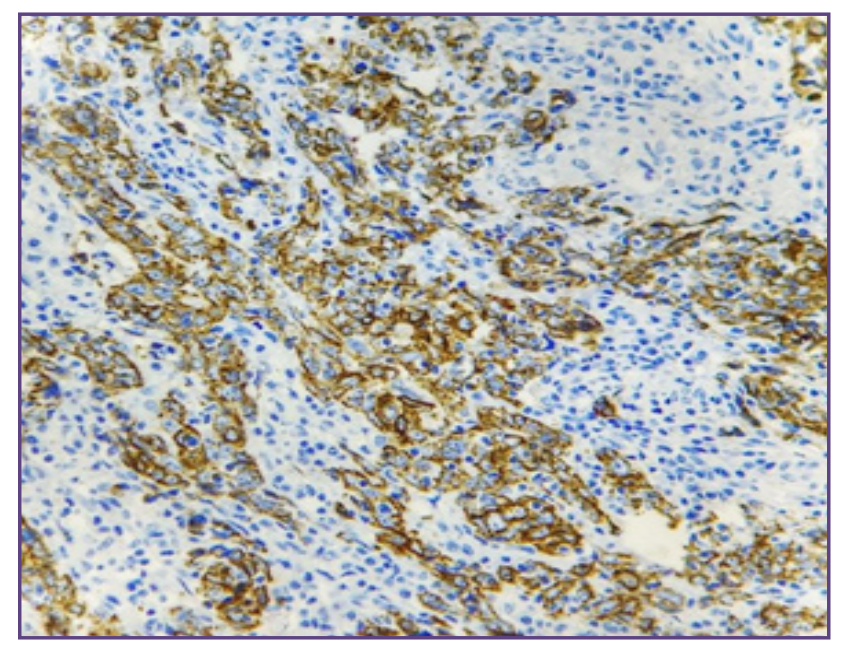

Fig. 2b: Sinonasal undifferentiated carcinoma showing strong pan-cytokeratin positivity. 


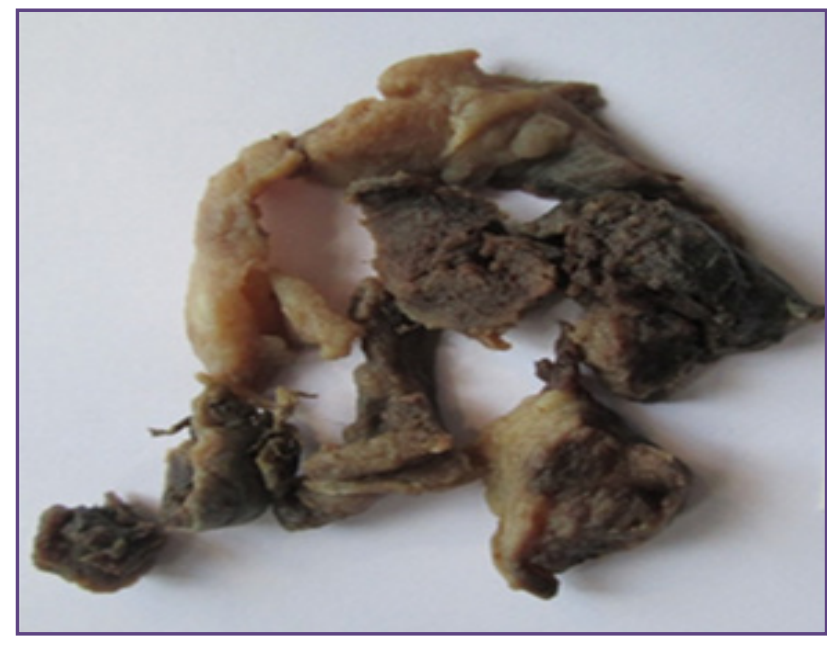

Fig. 3a: Neuroendocrine tumor, multiple fragmented, grayish white to tan tissue bits.

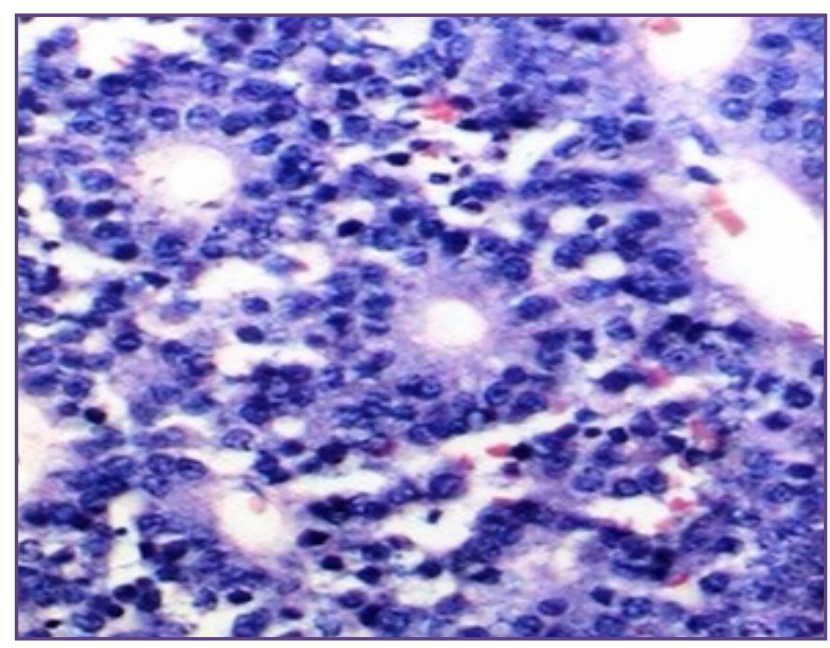

Fig. 3c: Neuroendocrine tumor showing rosette formation (H\&E, X400).

\section{Discussion}

We reported varieties of lesions involving the nose and paranasal sinuses, affecting all age groups and both sexes. No cases were seen in first decade. All patients presented with different symptoms, but nasal obstruction was the most common presentation. Imaging study reports were received in few cases. We divided these lesions into nonneoplastic and neoplastic.

Majority of lesions reported were non-neoplastic (82\%). In neoplastic lesions, benign tumours $(11.8 \%)$ were more common than malignant tumours $(5.5 \%)$. Parajuli et a ${ }^{[9]}$ reported $80.4 \%$ non-neoplastic lesion, $12.8 \%$ benign tumours and $6.8 \%$ malignant tumours. Similarly, Kulkarni et $\mathrm{al}^{[10]}$ reported $86.3 \%$ non-neoplastic lesion, $11.1 \%$ benign tumours and $2.6 \%$ malignant tumours. Thus, our study correlated well with these studies.

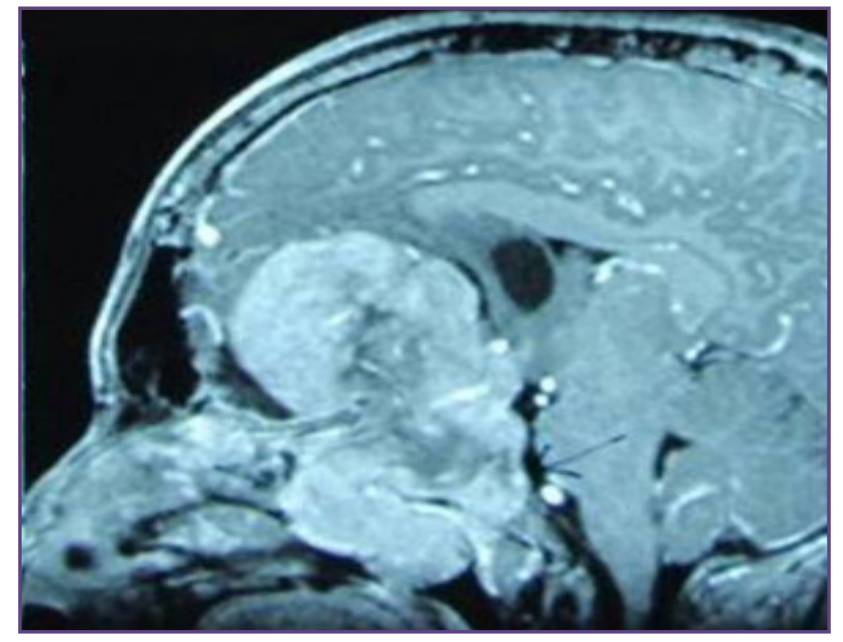

Fig. 3b: Neuroendocrine tumor, MRI showingtumour in sphenoid and ethmoidal sinus.

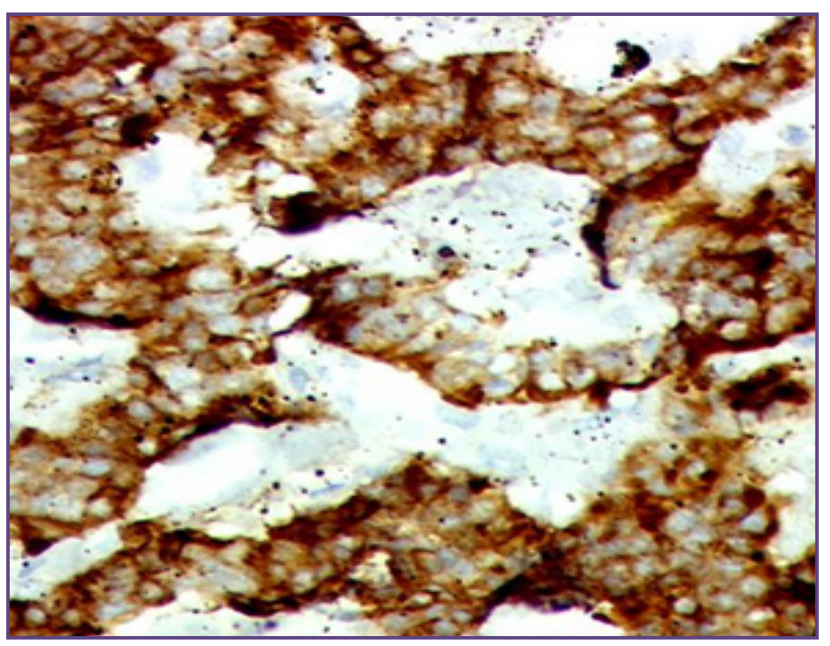

Fig. 3d: Neuroendocrine tumor showing strong chromogranin positivity.

Non-neoplastic lesions were seen mainly in the $3^{\text {rd }}-5^{\text {th }}$ decade of life. Most common age group affected was 21-30 years $(30.5 \%)$. They were least in the elderly age group. Humayun et $\mathrm{al}^{[5]}(31.4 \%)$ and Jyothi Raj et al ${ }^{[11]}$ $(46.2 \%)$ also reported higher incidence of non-neoplastic lesions in $3^{\text {rd }}$ decade. Parajuli et $\mathrm{al}^{[9]}$ reported majority of non-neoplastic lesions in $2^{\text {nd }} \& 3^{\text {rd }}$ decade. Males were predominantly affected with male to female ratio of $1.3: 1$. This was similar to Lathi et $\mathrm{al}^{[12]}$ (1.3:1) and Jyothi Raj et $\mathrm{al}^{[11]}(1.2: 1)$. Nasal obstruction was the most common clinical presentation seen in $84.7 \%$ cases, followed by nasal discharge $(55.2 \%)$. Humayun et $\mathrm{a}^{[5]}$ also reported nasal obstruction as the most common feature (100\%) followed by nasal discharge $(82.5 \%)$.

Out of 105 non-neoplastic lesions, nasal polyps were the most common lesions accounting $82.9 \%$. This was similar 
to studies conducted by Lathi et $\mathrm{a}^{[12]}(87.5 \%)$, Kulkarni et $\mathrm{al}^{[10]}(69.3 \%)$ and Parajuli et $\mathrm{al}^{[9]}(89 \%)$. The most common age group affected was $21-30$ years $(36.8 \%)$. The peak age of presentation in Jyothi Raj et al, ${ }^{[11]}$ Khan et al ${ }^{[8]}$ and Modh et $\mathrm{al}^{[2]}$ was also in the $2^{\text {nd }}$ and $3^{\text {rd }}$ decades of life. Male to female ratio was reported to be $1.2: 1$; similar to 1.3:1 in Jyothi Raj et al, ${ }^{[11]} 1.7: 1$ in Khan et al ${ }^{[8]}$ and 1.5:1 in Modh et al. ${ }^{[2]}$ Most common clinical presentation was nasal obstruction $(86.2 \%)$. Khan et $\mathrm{al}^{[8]}$ also reported nasal obstruction as presenting symptom.

Billroth (1864) described nasal polyps as neoplastic, but Zuckerlkandl considered them to be an inflammatory condition. Berdal(1959)was thefirst to introduce the practice of differentiating between benign and neoplastic conditions based on the histopathological classification. ${ }^{[13]}$ Several theories have been proposed to explain the pathogenesis of nasal polyp which include allergy, vasomotor imbalance, Bernoulli phenomenon, super antigen, aspirin intolerance and others. ${ }^{[14]}$ Davidsson and Hellquist ${ }^{[15]}$ classified polyps histologically into four categories: edematous or eosinophilic polyps, fibroinflammatory polyps, polyps with seromucinous gland hyperplasia and Polyps with stromal atypia. Our study showed large percentage of eosinophilic polyps (69\%) similar to Davidsson and Hellquist (86\%). Computerised tomography (CT) scan reported features of sinusitis or nasal polyp.

Fungal infections of nose and paranasal sinuses are increasingly recognized entity both in normal and immunocompromised individuals. Aspergillosis and Mucormycosis are the commonest of all fungal infections. ${ }^{[16]}$ Though clinical presentation and radiological findings may provide diagnostic clue for each fungal sinusitis category, histopathological examination and classification of fungal rhinosinusitis into invasive or non-invasive disease is important with regards to treatment. ${ }^{[17]}$

In the present study fungal rhinosinusitis was seen in the $4^{\text {th }}-7^{\text {th }}$ decade of life. Mean age of presentation was 50.7 years. Montane et $\mathrm{al}^{[18]}$ reported 50 years mean age group and Soontrapa et $\mathrm{al}^{[19]}$ reported 54.8 years mean age group. It was more common in males, with male to female ratio of 2:1. Male to female ratio in other studies were 1.8:1 in Navya et al ${ }^{[17]}$ and 1.2:1 in Montane et al. ${ }^{[18]}$ Most common clinical symptom in our study was nasal obstruction $(86.7 \%)$, followed by nasal discharge $(60 \%)$. Also in $33.3 \%$ of cases, there was history of diabetes mellitus. Wahid et $\mathrm{al}^{[20]}$ and Soontrapa et $\mathrm{a}^{[19]}$ also reported nasal obstruction as most common presenting symptom, $85 \%$ and $27.9 \%$ respectively. History of diabetes was seen in
$20 \%$ and $30.2 \%$ of cases in Wahid et al ${ }^{[20]}$ and Soontrapa et $\mathrm{al}^{[19]}$ studies respectively. Imaging studies in few cases received, reported features of polyp or mucosal thickening.

Rhinosporidiosis is a chronic granulomatous infectious disease, characterized by hyperplastic polypoid lesions of the mucous membrane. Ashworth, after a study of Rhinosporidium, proved that it was not a sporozoa, but belonged to the group phycomycetes in the sub-order of Chytridineae, and called it Rhinosporidiumseeberi, which has become its accepted name. Majority of cases are reported from India, Srilanka and Bangladesh. It usually presents as single or multiple, pedunculated or sessile masses, pink to deep red in colour, usually described as strawberry like appearance. They bleed easily with a history of nasal obstruction or epistaxis.

We reported 3 cases of rhinosporidiosis, two in the age group of 21-30 years and one in 11-20 years age group. They presented mostly with nasal obstruction. Incidence of rhinosporidiosis in our study was similar to Nayak et al ${ }^{[21]}$ $(1.82 \%)$ and Lathi et $\mathrm{al}^{[12]}(2.5 \%)$.

Benign tumours were reported commonly in $4^{\text {th }}$ decade $(26.7 \%)$. Parajuli et $\mathrm{al}^{[9]}$ and Lathi et $\mathrm{al}^{[12]}$ reported benign tumours commonly in the $5^{\text {th }}$ decade. Males were predominantly affected than females. Male to female ratio was $4: 1$. Lathi et $\mathrm{al}^{[12]}(1.7: 1)$ and Jyothi Raj et $\mathrm{al}^{[11]}(1.5: 1)$ reported similar male predominance. Nasal obstruction was the most common clinical feature ( $80 \%)$, followed by nasal discharge $(53.3 \%)$ and epistaxis $(53.3 \%)$. Humayun et $\mathrm{al}^{[5]}$ also reported nasal obstruction as most common symptom (66.7\%). Nasal discharge and epistaxis was also common feature in Humayun et al ${ }^{[5]}$ study.

Inverted papillomas are two to five times more common in males and are found primarily in the 40-70 year age group. These papillomas characteristically arise from the lateral nasal wall in the region of the middle turbinate or ethmoid recesses. Unilateral nasal obstruction is the most common presenting symptom. Grossly, these are pink, tan, or gray; non-translucent; soft to moderately firm polypoid growths with a convoluted or wrinkled surface.

We reported 6 cases of inverted papilloma in our study. Majority of patients presented in the $4^{\text {th }} \& 5^{\text {th }}$ decade of life $(66.6 \%)$. Male to female ratio was $5: 1$. Nasal obstruction was the most common clinical presentation (83.3\%), followed by epistaxis (50\%) and nasal discharge $(50 \%)$. Khan et $\mathrm{al}^{[8]}$ reported 15 cases of inverted papilloma. The peak age of presentation was fifth decade of life and the male to female ratio was $3: 1$. Jaison et al ${ }^{[22]}$ reported 5 cases of inverted papilloma. Most common age group affected was $5^{\text {th }} \& 6^{\text {th }}$ decade and male to female ratio was $4: 1$. Most common clinical presentation was nasal obstruction 
and epistaxis. CT scan findings in one case showed left maxillary, sphenoid, ethmoidal sinusitis with left nasal polyp and in one case Magnetic resonance imaging (MRI) suggested features of left sphenoid, maxillary sinusitis.

Angiofibroma usually presents with nasal obstruction. The gross appearance of the neoplasm is of a lobulated, pink to purplish, smooth surfaced mass.

We reported 4 cases of angiofibroma. Males were most commonly affected than females and male to female ratio was $3: 1$. Most common clinical symptoms were nasal obstruction (75\%) and epistaxis (75\%). Parajuli et al ${ }^{[9]}$ reported 3 cases of angiofibroma with profuse recurrent epistaxis as chief complaint. Jaison et al ${ }^{[22]}$ reported 5 cases of angiofibroma in first two decades of life and male to female ratio was $4: 1$.

Solitary fibrous tumor was reported in a 50 year male with complaints of nasal obstruction and discharge. CT scan reported polypoidal mucosal thickening involving all the sinuses and nasal cavities. Immunohistochemically tumor cells showed diffuse cytoplasmic positivity for CD34 and CD99 (Fig. 1a \& 1b). Other benign tumours included single cases of lobular capillary hemangioma, osteoid osteoma, ossifying fibroma andgiant cell reparative granuloma.

Malignant tumours were seen in the age range from 1970 years. $71.4 \%$ of cases were seen in the $6^{\text {th }} \& 7^{\text {th }}$ decade. Jyothi Raj et al ${ }^{[11]}$ reported $62.5 \%$ of malignant lesions in the $6^{\text {th }}$ decade. Parajuli et a ${ }^{[9]}$ reported $60 \%$ cases of malignant tumours in the $5^{\text {th }}-7^{\text {th }}$ decade. Thus malignant tumours in our study were more common in elderly patients, similar to other studies. Malignant tumours were common in females. Male to female ratio was 1:2. Female dominance was also seen in studies conducted by Jyothi Raj et $\mathrm{al}^{[11]}(1: 1.7)$ and Bijjaragi et al ${ }^{[23]}$ (1:1.6). Nasal obstruction (71.4\%) and epistaxis $(71.4 \%)$ were the most common symptoms, followed by nasal discharge, facial swelling, headache, loss of smell and eye related symptoms. Humayun et al $\mathrm{l}^{[5]}$ also reported nasal obstruction $(100 \%)$ as most common symptom followed by epistaxis $(75 \%)$.

Sinonasal undifferentiated carcinoma typically presents as a rapidly enlarging tumor mass involving multiple sites of the sinonasal tract, often with evidence of extension beyond the anatomic confines. The pathogenesis still remains unknown. Epstein - Barr virus has been implicated as a potential pathogen. ${ }^{[24]}$ The most common initial symptoms are epistaxis, facial pain, and nasal obstruction.

We reported 4 cases of sinonsasl undifferentiated carcinoma. Two cases were reported in $6^{\text {th }}$ decade, one in $7^{\text {th }}$ decade and one in $3^{\text {rd }}$ decade. Male to female ratio was 1:3. Nasal obstruction was most common presenting symptom in all cases. CT scan report was available in one case which showed mass involving left maxillary, ethmoid, sphenoid sinus. Immunohistochemically tumor cells showed Pancytokeratin positivity in all cases (Fig. 2a \&2b).

Bijjaragi et $\mathrm{al}^{[23]}$ reported two cases of sino-nasal undifferentiated carcinoma, one each in male and female. In study by Kalpana Kumari et al ${ }^{[25]}$ malignant tumours were seen in $50 \%$ of the neoplastic cases and majority were sinonasal undifferentiated carcinomas (41\%).

Sinonasal squamous cell carcinomas occur most frequently in the maxillary sinus. ${ }^{[26]}$ Symptoms include nasal obstruction; epistaxis; rhinorrhea; pain; paraesthesia; swelling of the nose or cheek or a palatal bulge; nasal mass; or, in advanced cases, proptosis, diplopia, or lacrimation. ${ }^{[26]}$

We reported a single case of keratinizing squamous cell carcinoma in a 70 years female with complaints of nasal obstruction, nasal discharge, epistaxis and facial swelling.

Neuroendocrine neoplasms are defined as epithelial neoplasms with predominant neuroendocrine differentiation. The clinical features of sinonasal neuroendocrine carcinoma are nonspecific and similar to those of other sinonasaltumours. Common presentations include nasal obstruction, epistaxis, facial mass, and/or facial pain.

A single case of sphenoid sinus neuroendocrine tumour was observed in a 51 years male patient with complaints of headache. MRI suggested pituitary tumour involving sphenoid and ethmoidal sinus. Immunohistochemistry showed positivity for cytokeratin and chromogranin (Fig. 3a, 3b, 3c \&3d).

\section{Conclusion}

It was found that varieties of lesion affect the nose and paranasal sinuses, which included non-neoplastic and neoplastic lesions. Non-neoplastic lesions outnumbered the neoplastic lesions. Inflammatory nasal polyps were most common lesion. Non-neoplastic lesions and benign tumours affected predominantly middle age group and neoplastic lesions were common in elderly patients. Males were predominantly affected but malignant tumours were seen more in females. Nasal obstruction was the most common symptom in all lesions. Imaging studies were not always conclusive.

To conclude, sino-nasal masses or polyps can be nonneoplastic or neoplastic lesions and histopathological examination remains the mainstay in differentiating these lesions.

\section{Reference}

1. Lingen MW. Head and neck. Chapter 16; In Kumar V, Abbas A K, Fausto N, Aster J C, eds. Robbins and Cotran Pathologic basis of disease, 8th ed. Elsevier: Haryana, India; 2010:751-2. 
2. Modh SK, Delwadia KN, Gonsai RN. Histopathological spectrum of sinonasal masses- A study of 162 cases. Int J Cur Res Rev 2013; 5(3): 83-91.

3. Hedman J, Kaprio J, Poussa T, Nieminen MM. Prevalence of asthma, aspirin intolerance, nasal polyposis and chronic obstructive pulmonary disease in a population-based study. Int J Epidemiol. 1999 Aug; 28(4): 717-22.

4. Barnes L, Tse LL, Hunt JL, Gensler BM, Curtin HD, Boffetta P. Tumours of the nasal cavity and paranasal sinuses. In: Leon B, John WE, Peter R, David S, editors. IARC WHO classification of tumours, pathology and genetics of head and neck tumours. Lyon: IARC Press:2005.9-82.

5. Humayun AHM, ZahurulHuq AHM, Ahmed SMT et al. Clinicopathological study of sinonasal masses. Bangladesh J Otorhinolaryngol 2010;16:15-22.

6. Gupta N, Kaur J, Srinivasan R, Das A, Mohindra S, Rajwanshi A, et al. Fine needle aspiration cytology in lesions of the nose, nasal cavity and paranasal sinuses. ActaCytol 2011;55:135-41.

7. Nigam JS, Misra V, Dhingra V, Jain S, Varma K, Singh A. Comparative study of intra-operative cytology, frozen sections, and histology of tumor and tumor-like lesions of nose and paranasal sinuses. J Cytol 2013;30:13-7.

8. Khan N, Zafar U, Afroz N, Ahmad SS, Hasan S. Masses of nasal cavity, paranasal sinuses and nasopharynx: a clinicopathological study. Indian Journal of Otolaryngology and Head and Neck Surgery 2006;58(3):259-63.

9. Parajuli S, Tuladhar A. Histomorphological spectrum of masses of the nasal cavity, paranasal sinuses and nasopharynx. J Pathol Nepal 2013;3:351-5.

10. Kulkarni AM, Mudholkar VG, Acharya AS, Ramteke RV. Histopathological Study of Lesions of Nose and Paranasal Sinuses. Indian J Otolaryngol Head Neck Surg 2012;64(3):275-279.

11. Jyothi A Raj, Sharmila PS, Mitika Shrivastava, Mahantachar $\mathrm{V}$, T Rajaram. "Morphological spectrum of lesions in the sinonasal region". Journal of Evolution of Medical and Dental Sciences 2013;2,(37)7175-7186.

12. Lathi A, Syed MMA, Kalakoti P, Qutub D, Kishve SP. Clinicopathological profile of sinonasal masses: a study from a tertiary care hospital of India. Acta Otorhinolaryngol Ital 2011;31(6):372-7.

13. Venkatarajamma K, Joshyam S, Gowda B, Zebanoorain. Clinic-Pathological Profile of Sinonasal Masses. Int J Gen Med Pharm 2015;4(2):7-18.
14. Tikaram A, Prepageran N. Asian nasal polyps: a separate entity? Med J Malaysia 2013;68(6):445-7.

15. Davidsson A, Hellquist HB. The So-Called “Allergic" Nasal Polyp. ORL J Relat Spec 1993;55:30-5.

16. Joshi SR, Nagare M. Case report Fungal Rhinosinusitis ( Aspergillosis ) -3 cases. 2015;4(2):314-7.

17. Navya BN. Role of Histopathology in the Diagnosis of Paranasal Fungal Sinusitis. J Dent Med Sci 2015;14(1):97-101.

18. Montone KT, Livolsi V a., Feldman MD, Palmer J, Chiu AG, Lanza DC, et al. Fungal Rhinosinusitis: A Retrospective Microbiologic and Pathologic Review of 400 Patients at a Single University Medical Center. Int J Otolaryngol 2012;12:1-9.

19. Soontrapa $P$, Larbcharoensub N, Luxameechanporn T. Fungal rhinosinusitis: a retrospective analysis of clinicopathologic features and treatment outcomes at ramathibodi hospital. Southeast Asian J Trop Med Public Health 2010;41(2):442-9.

20. Fazal-I-Wahid, Adil Khan, Iftikhar Ahmad Khan. Clinicopathological profile of fungal rhinosinusitis. Bangladesh J Otorhinolaryngol 2012;18(1):48-54.

21. Nayak M, Roul B, Agrawal K, Nayak S. Clinicopathological study of lesions of sinonasal tract \& Distribution of Sinonasal tract lesions in difefferent age groups \& Sex. International Journal of Advanced Research 2015;3(4):726-733.

22. Jaison J, Tekwani DT. Histopathological lesions of nasal cavity, paranasal sinuses and nasopharynx. Annals of Applied Bio-Sciences 2015;2(2):40-6.

23. Bijjaragi S, Kulkarni VG, Singh J. Histomorphological study of polypoidal lesions of nose and paranasal sinuses. Indian Journal of Basic and Applied Medical Research 2015;4(3):435-9.

24. Mohammed AW, Bakshi J, Nada R. Sinonasal undifferentiated carcinoma with contralateral cavernous sinus involvement - A rare presentation. Curr Res Microbiol Biotechnol 2013;1(2):58-61.

25. Kalpana Kumari MK, Mahadeva KC. Polypoidal lesions in the nasal cavity. J Clin Diagn Res. 2013 Jun;7(6):1040-42.

26. Santos MRM, Servato JPS, Cardoso SV, Faria PR De, Eisenberg LA, Dias FL, et al. Squamous cell carcinoma at maxillary sinus : clinicopathologic data in a single Brazilian institution with review of literature. Int J Clin Exp Pathol 2014;7(12):8823-32.

*Corresponding author:

Dr. Prashant Shivaji Mane, Department of Pathology, Grant Government Medical College, Mumbai Maharashtra 400008. India

Phone: +91.9766855956

Email: prashantmane0791@gmail.com

Financial or other Competing Interests: None.

Date of Submission : 15.12.2016

Date of Acceptance : 01.04.2017

Date of Publication : 05.06.2017 